Relations industrielles

Industrial Relations

\title{
Le délai-congé
}

Volume 4, numéro 8, avril 1949

URI : https://id.erudit.org/iderudit/1023515ar

DOI : https://doi.org/10.7202/1023515ar

Aller au sommaire du numéro

Éditeur(s)

Département des relations industrielles de l’Université Laval

\section{ISSN}

0034-379X (imprimé)

1703-8138 (numérique)

Découvrir la revue

Citer cet article

(1949). Le délai-congé. Relations industrielles / Industrial Relations, 4(8), 78-78. https://doi.org/10.7202/1023515ar

Tous droits réservés (C) Département des relations industrielles de l’Université Laval, 1949
Ce document est protégé par la loi sur le droit d'auteur. L’utilisation des services d'Érudit (y compris la reproduction) est assujettie à sa politique d'utilisation que vous pouvez consulter en ligne.

https://apropos.erudit.org/fr/usagers/politique-dutilisation/
Cet article est diffusé et préservé par Érudit.

Érudit est un consortium interuniversitaire sans but lucratif composé de l'Université de Montréal, l'Université Laval et l'Université du Québec à

Montréal. Il a pour mission la promotion et la valorisation de la recherche.

https://www.erudit.org/fr/ 


\section{LE DÉLAI-CONGÉ}

Le législateur à la fin du siècle dernier formula des règles sur la rupture du contrat de travail; elles se trouvent à la Loi des maîtres et des serviteurs (S.R.Q., 1941, c. 328). Suivant ce statut, le délai-congé pouvait être arrêté dans les cités et villes, par un règlement municipal et ailleurs l'était par les dispositions de cette loi.

Elle visait les domestiques, serviteurs, compagnons et journaliers, en un mot, les ouvriers; elle s'appliquait à ceux qui s'étaient engagés pour une période indéterminée. Leur contrat de travail ne pouvait être rompu de part et d'autre sans un avis de délai-congé.

Mais les dispositions de cette loi ne répondaient plus à notre éthique sociale, car elle prévoyait l'amende pour l'abandon du travail sans avis. De nombreuses bonnes et apprenties durent affronter les cours pour avoir laissé en plan leurs employeurs.

Le législateur à la dernière session par le statut 13 Geo. VI, c. 69 a abrogé la Loi des maîtres et des serviteurs ainsi que les règlements municipaux adoptés sous son empire. La Loi de l'engagement des pêcheurs, (S.R.Q., 1941, c. 329), statut au même effet, fut également abrogée.

Le paragraphe suivant fut introduit au Code civil à l'article 1668:

«Dans le cas d'un domestique, serviteur, compagnon ou journalier engagé à la semaine, au mois ou à l'année, mais pour un laps de temps indéfini, il peut être mis fin au contrat par avis, de l'une des parties à l'autre, d'une semaine, si l'engagement est à la semaine; de deux semaines, si l'engagement est au mois; d'un mois, si l'engagement est à l'année. »

Ce nouvel article fixe suivant le mode de paye la longueur du délai-congé, explicitant la règle des articles 1642 et 1657 du Code civil applicable aux autres salariés engagés pour une durée non déterminée.

\section{LES RÉFORMES DE STRUCTURE}

Depuis quelque temps, on parle de réformes de l'entreprise dans beaucoup de milieux.

Les uns prennent immédiatement la mouche, crient à la révolution ou au renversement de l'ordre établi alors qu'à peine commence le cheminement de ces idées contenues en principe dans les encycliques sociales des souverains pontifes.

Les autres - et c'est heureusement le cas de la majorité, encore qu'ils pétaradent moins haut, - d'un jugement moins superficiel s'efforcent plutôt d'étudier objectivement ces données nouvelles afin de voir s'il est possible, par une évolution à la fois prudente et audacieuse, d'en assurer l'application raisonnable de manière à purger l'économie moderne des abus d'un capitalisme anonyme et toutpuissant.

Telle est la première constatation qui vient à l'esprit de celui qui se donne la peine de parcourir attentivement une brochure publiée il y a quelques jours à peine, en français et en anglais, par le Département des relations industrielles de la Faculté des sciences sociales de l'Université Laval sous la signature de MM. les abbés Gérard Dion et Paul-Emile Bolté ainsi que de Marcel Clément. Cette brochure s'intitule: «Réformes de structure dans l'entreprise ». ${ }^{1}$

(1) «Réformes de structure dans l'entreprise » est en vente au Département des relations industrielles de l'Université Laval, Québec, au prix de \$1.00.
Dans une introduction fort à point, M. l'abbé Gérard Dion pose froidement le problème en rappelant qu'il y a déjà seize ans, dans l'encyclique Quadragesimo Anno, Sa Sainteté Pie XI lançait le mot d'ordre: Réforme des moeurs, réformes des institutions.

«Les réformes de structures, dans le domaine des relations du travail, écrit-il, se posent sur le plan de lentreprise, de la profession et de la nation. Elles ont pour base le problème de la propriété et de sa distribution sous toutes ses formes. Cependant, on ne peut pas oublier non plus que l'enjeu du conflit entre les patrons et les ouvriers n'est pas seulement une question de piastres et de cents, mais une répartition nouvelle de l'autorité et une reconnaissance pratique de la dignité humaine. Voilà pourquoi, nous avons l'intention, sans courir l'aventure dans les fossés de gauche et de droite mais en nous basant sur la doctrine sociale de l'Eglise, qui est assez féconde par elle-même, et sur les réalités sociales telles qu'elles se présentent chez nous, de repenser les conceptions que l'on se fait des régimes de la propriété, de l'entreprise, du capitalisme, du profit, de l'autorité dans les relations du travail, de la participation à la propriété, à la gestion et au profit de l'entreprise. »

Les études de la brochure portent sur les réformes de structure au sein de l'entreprise. C'est la base. Inutile, en effet, de songer à réformer la profession et, encore moins, l'économie dans son ensemble, si les fondements font défaut, s'ils ne s'adaptent plus à la condition actuelle des employeurs et des salariés, si la rupture est totale 